AP: Ontine Journat in Public Archaeology Special Volume 3 - 2018 p. 177-194

\title{
Open Data as Public Archaeology: \\ The Monumental Archive Project
}

Katherine COOK

University of Montreal

Received: 04/09/2017 - Accepted: 30/06/2018

\begin{abstract}
The value of open data is transforming archaeological practice while also introducing new concerns relating to the ethics of studying the dead. This paper uses the Monumental Archive Project, recently launched as a public database of cemetery records from Barbados, as a case study to critically examine the realities of platforms created to bring together academic and general audiences in open mortuary archaeology. Digital literacy and support structures are significant barriers to digital data within the discipline, while the impact of open data on the public(s) that archaeologists seek to engage and collaborate with is rarely considered let alone measured. Is it possible to serve diverse audiences and represent diverse people in the past with a single platform? What are the implications (social, ethical, emotional) for sharing cemetery data? When digitizing the dead, strategies in platform design, marketing and communication for public interest and use become even more complex and necessitate further attention.
\end{abstract}

\section{Keywords}

Caribbean, cemetery, digital archaeology, data, historical archaeology 


\section{Introduction}

Cemeteries are a delicate balance between public and private; funerary monuments in particular are at once motivated by public retrospection and private grief and emotion (Cannon and Cook 2015; Thomas 2009: 245). For archaeologists engaged in monument studies-those whose work rests largely above rather than below ground and therefore can be carried out without lifting a trowel or collecting a single artefact-the public nature of cemeteries has long been a benefit. Large datasets are ripe for the recording, with seemingly few ethical or legal restrictions in comparison to research associated with human remains and excavation. At the same time, this work has remained relatively private; results are difficult to access outside of academic publications, raw data is rarely shared, and the localized focus often leaves these studies in isolation. The exclusive nature of this research climate, then, has long eclipsed the public dimensions of recording, interpreting and publishing monuments and their histories.

In the twenty-first century, the tension between public and private, inclusiveness and exclusiveness, seems ever more acute. With millions of popular media stories posted on social media featuring burial grounds and monuments (Figure 1), and taphophile cyber-communities and crowd-sourced web archives of cemeteries from around the world, personal grave markers can easily 'go viral'. The genealogy industry is also booming (Kramer 2011), with data brokers such as Ancestry.com cashing in on the dead (Booth this vol.). The fields of archaeology and history have similarly been transformed, consumed with redeveloping methods for archiving, accessing, and preserving digital records (Tibbo 2003: 9). The values and protocols of open science ${ }^{1}$ have especially pushed scholars to critically reflect on the accessibility of not only interpretations, but also on data (Kansa 2012; Lucas 2012: 216)-for professionals and for the public alike. Initiatives such as Camp's (2017) experiments with augmented reality to connect historical records and narratives to a local cemetery, and Dundee Howff Conservation Group's (2017) open 3D models of monuments, demonstrate growing creativity and innovation in cemetery preservation and heritage practice. At

1 Open science is traditionally framed as a barrier-free revolution that removes traditional fees, copyright and licensing restrictions, and other economic/physical obstacles to participating in or accessing science (Suber 2012: 4). 
the same time, there are rising concerns amongst communities and stewards of funerary landscapes about sharing personal information recorded on monuments, if not the monuments themselves, as potential threats to their privacy, grief and memory. The online shaming of individuals who do not show appropriate respect for

(0) Instagram

(1) Instagram
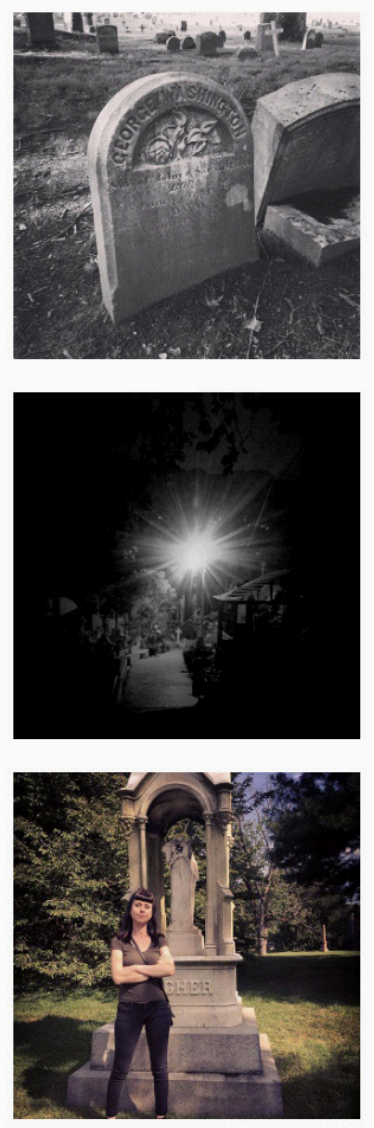

a Search

\#cemetery

$1,366,795$ posts
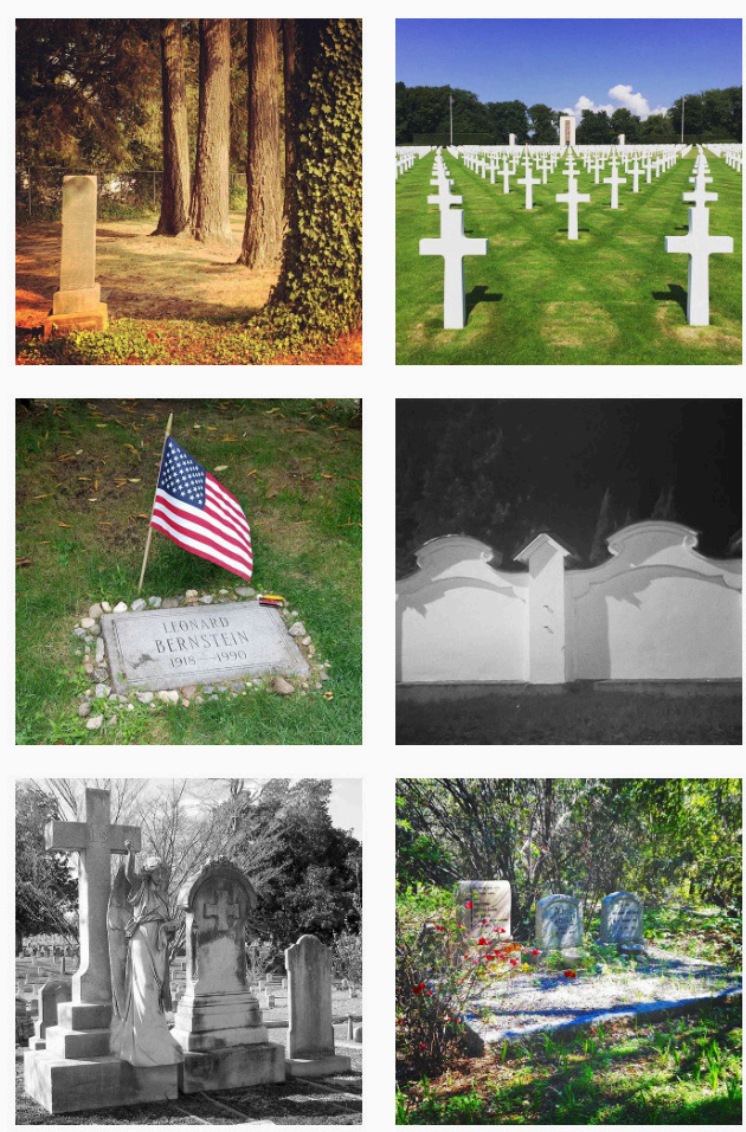

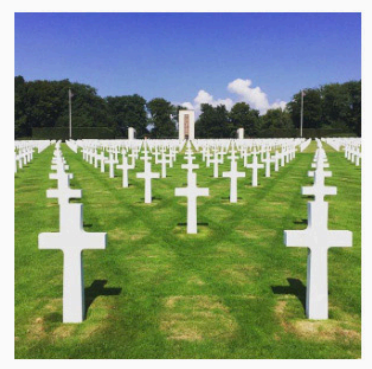

(a) $0 \stackrel{\circ}{\circ}$

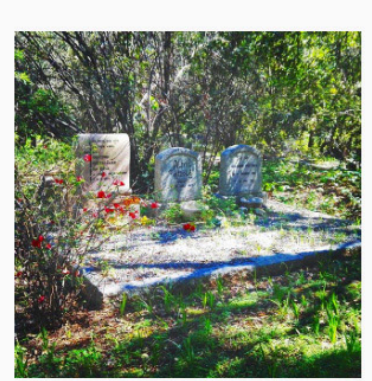

Figure 1: Screenshot of recent \#cemetery images posted on Instagram. 
the dead (for instance, at Holocaust memorials (Shapira 2017) or Pokémon GO users who played in cemeteries (Judge and Brown 2017)), also demonstrates, however that objections are more complicated than simply questions of rights, logistics and intellectual property, but that these objections intersect with the diverse ways in which people understand and connect with death and the dead. In many ways, professional archaeologists and historians have not fully dealt with the ethics and politics of recording historic cemeteries and monuments in pre-digital formats; and thus have no basis upon which to adapt and extend this in considering the way the web has transformed issues of access, long-term preservation, and licensing/ restrictions. ${ }^{2}$ These issues have proven extremely complex, contextspecific and demand advanced understandings of ever-changing digital technology coupled with strong collaborations with informed communities.

This article uses the Monumental Archive Project (Cook 2016a), recently launched as a public database of cemetery records, as a case study to critically examine the realities of digital platforms created to bring together academic and general audiences in open mortuary archaeology. Although the growing popularity of current digital platforms which share information about cemeteries and burial sites (e.g. ancestry.com and findagrave.com) demonstrates a ready audience, unsystematic data collection and issues with ethics, access, and cost may limit their usefulness and flexibility. Meanwhile, archaeology of historical funerary commemoration, which has increasingly included outreach activities like open days, public lectures, and community training, rarely produces public research resources, limiting broader engagement, but also democratizing/ decolonizing data through changing structures of power and making space for more diverse voices, expanding sample sizes and comparative analysis. This is paralleled by a divide in digital heritage (and digital scholarship more broadly) where a lack of critical evaluation of digital methods and theory continues to create tension between applications intended for professional and public audiences despite overlapping entry points, communication networks, and the social dimensions of inequalities, expert knowledge and power (Lupton 2014; Richardson and Lindgren 2017: 139-41). Altogether,

2 For more detailed discussion of the electronic distribution revolution, see Kansa 2012: 498-99. 
data created through commercial, academic, and community avenues continues to be dominated by white historical narratives, often restricting the (perceived) usefulness of data and its relevance to contemporary research and understandings of the past. Cemetery data recording and sharing must become a wholly collaborative project between communities and scholars, recognizing problems of underrepresentation, the spectrum of digital literacies, attitudes towards digitizing monuments and sacred spaces, and historical legacies of dominance and power. This article will discuss whether it is possible to serve diverse audiences with a single platform. It will explore the implications (social, ethical, emotional) for sharing cemetery data. Furthermore, it will ask how can we gauge the impact of these resources? When digitizing the dead, strategies in platform design, marketing, and communication for digital archaeology become even more complex and necessitate further attention.

\section{Project Background}

The Monumental Archive Project (MAP) was developed to act as an open database of historic cemeteries to address accessibility and sustainability issues whilst stimulating new approaches to traditional archaeological research. Its primary goals were to:

(1) preserve and provide access to existing records;

(2) stimulate new research and engagement with historic cemeteries (an at-risk heritage resource) through data reuse;

(3) and establish collaborative networks between diverse interest groups.

To do so, the project set out to develop a web-based interface (Figure 2) structured around an open database of curated ${ }^{3}$ collections (contributed by researchers, community members/ groups, archives), which could be interacted with in a variety of ways, could be expanded as opportunities arose, and could be used

3 Data curation is critical to creating standardized, compatible and easily reusable data (i.e. edited for mistakes in data entry, inconsistent vocabulary, etc.). For more detailed discussion of data curation and publishing standards in archaeology, see Huggett (2015), Kansa et al. (2014). 
to advocate for more open data in this area of research. The pilot content used records of intramural and extramural monuments in Barbados (approximately 2500 monuments located at sixteen Anglican churches and four plantations), from previous research conducted by the author, including inscriptions, location, and material descriptions (style, iconography, font, material) (Cook 2016b). This data was selected in part for practical reasons of access, but more importantly in recognizing its representation of diverse groups of people, tackling the underrepresentation of race and gender in many historical datasets.

The platform proposed bringing together the archaeological/ historical communities (academic, professional) and the 'public' (i.e. descendants, genealogists, local historical societies) to encourage collaboration, education, and research/discovery. The academic/ professional side of historical cemetery research, particularly associated with monument studies, has long established practices

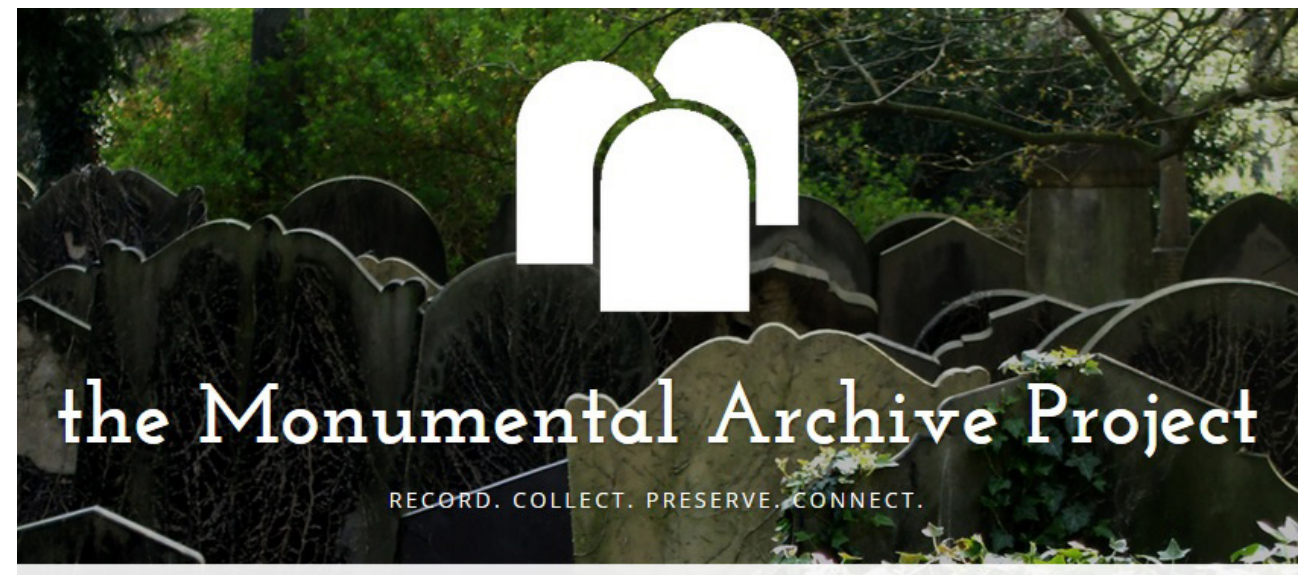
HOME
ABOUT
COLLECTIONS
BLOG
CONTACT

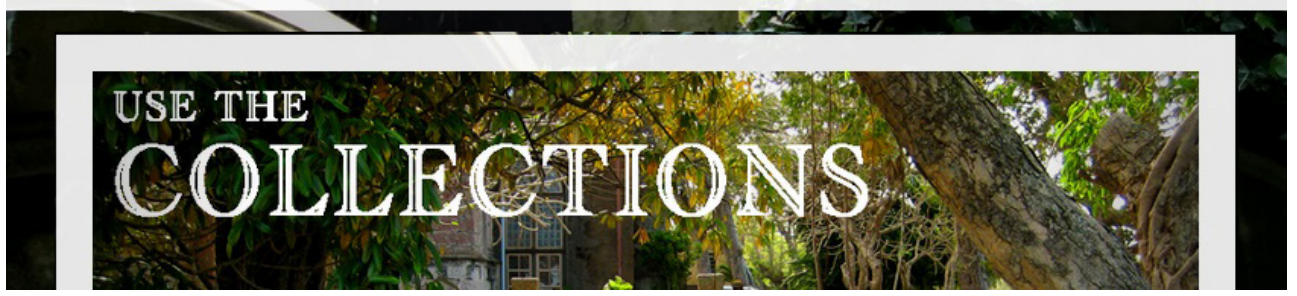

Figure 2: Web-based interface for the Monumental Archive Project. 
for recording, but there has been very little sharing of raw data. Likely influenced largely by academic cultures of publication, career trajectories and competitiveness, data sharing has only recently shifted to become a priority in archaeological circles (Kansa 2010; 2012). As such, further examples of databases and research facilitated by open data are needed for it to gain traction within cemetery studies, and more broadly. This website sought to encourage open access to records generated by academic/ professional researchers with the benefit of being able to generate larger datasets, comparative studies, and new collaborations, as well as gain exposure through citations and public interfaces. The general public also has a long history of recording cemeteries of genealogical and local historical interest (Cook 2017b: 34). As in many places, the burial grounds of Barbados have been, for example, repeatedly recorded by communities and genealogists resulting in three surviving sets of transcriptions (Lawrence-Archer 1875; Oliver 1915; Thorne n.d.). Records like these are most often text only (lacking details of form, ornamentation, and material) maintained by local historical societies and archives, but are rarely accessible through compatible, digital platforms and usually only after the payment of a fee (to assist with preservation and maintenance costs). The cost of travel to archives or to purchase access to records, however, is often prohibitively expensive, limiting accessibility and inclusivity of heritage resources. MAP therefore also made it a goal to explore low-cost options for data sharing and preservation to increase access and build more understanding of recording, interpretive and digital archiving practices.

The project was designed to use entirely free and open source software. In the face of many large-scale Digital Humanities endeavours that highlight the big, high-tech and expensive solutions, this was an exploration of what could be achieved in the digital world without any kind of a budget. The web-based platform was built on Github, using the free hosting option of ghpages (as an alternative to high-cost web solutions). The front-end of the website was designed to be user-friendly, adaptable and scalable. The landing page includes an interactive map to explore the collections (Figure 3). The pilot data, in compatible CSV format, was used to create a searchable HTML table, where users can seek out specific family names, locations, types of monuments, and 

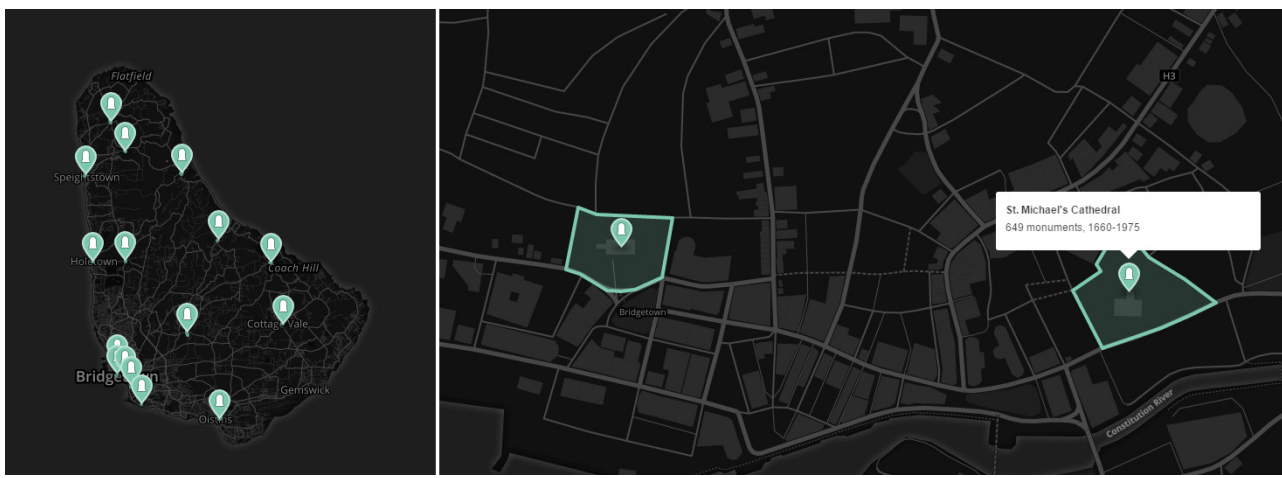

Figure 3: Interactive maps provide one method for exploring the data records available.

other dimensions. It is also available to download, which permits users to import the data directly into their own data analysis software for more intensive research. Images and maps of each monument and churchyard are supplemental resources for viewing and downloading. The website was also coded as much as possible for accessibility, including recognizing the need to be compatible with text-to-speech software, as well as options for enlarging text and images. Analytics services ${ }^{4}$ were deployed to measure interactions with the web-platform and data downloads over time. However, this data is limited by the inability of the service to differentiate between professional and public users and identify patterns in their online practices, nor more nuanced differences in demographics (age, gender, ethnicity, etc.). This information about users was supplemented by recording and analysis of engagement evident through social media platforms and other web-based communications, however as a result it is more anecdotal than systematic. In future, further examination of website usage and experiences is necessary to refine the observations and conclusions

4 These analytics were largely collected through Google Analytics, but also through analytics embedded in social media platforms. It should be noted that there are concerns with the ethics and privacy implications of these types of data collection and who has access to this data (commercial appropriation and use, etc.). This is a concern and is one that should be further considered in anthropological and community-based settings, particularly since, although Google Analytics is something that websites opt in to, for many platforms that data is collected whether the content creators want it to be or not. How do we make choices about the capture and use of analytics? And how do we ensure users are aware of the ways their data may be collected and shared? 
presented below, perhaps through more intentional surveys and engagement with users.

\section{Discussion: An Ongoing 'Post-Mortem'}

Because no precedent exists, MAP was from the outset a series of exploratory experiments in digital archaeology and public heritage. Framed by the motivation to make publicly funded research data publicly accessible, and more broadly to act as a catalyst for further collaboration between academics and communities, the launch of the web platform in August 2016, and the year since, have provided a series of lessons in digital public mortuary archaeology.

\section{Open Cemeteries for Data Sharing}

The public nature of open data platforms for cemetery research is complicated to say the least. Protocols and discourse on the digitization of the dead pertain largely to human skeletons (cf. Márquez-Grant and Errickson 2017), which likely stems from the broader trend in archaeology to focus ethical concerns on bodies rather than material culture, monuments, and landscapes. The ethics of open databases of monuments, on the other hand, falls within an ethical grey area, caught between the ambiguities of the public domain and private ownership. If monuments are too recent, there are concerns with the copyright of stonemasons and the personal information recorded on monuments. If the monuments are much older, there are concerns about the ethics of digitizing objects associated with the dead, when it would often be impossible to seek photo permissions and data sharing consent from next of kin. There is also an impact on cemeteries, churchyards, and historical societies, many of whom rely on the funds raised by selling photo rights/licenses, historical records and genealogical services. ${ }^{5}$ However, many of these groups also rely on public funds

5 Cemetery and monument records are frequently used to generate revenue for public and private organizations, from historical societies selling records (in paper or locked digital formats) to platforms like Find-A-Grave and Ancestry.com selling ads or memberships. There is a secondary debate here that is too broad for this paper to tackle concerning the ethics and legalities of possessing or selling rights to monuments that were erected by families, exist in publicly accessible spaces, and often are maintained by public groups. 
for conservation efforts and heritage initiatives, further blurring the lines between public and private rights.

Digital records, including photographs and models, inscriptions, and geographic locations, are critical to the preservation and monitoring of monuments and cemeteries, which are subject to weathering, accidental destruction and vandalism (Cook 2011: 7282). Moreover, as Williams (2016) has argued, 'there are absolutely no theological or traditional religious or social reason why recording gravestones in any fashion, including photography, can be construed as an inherently disrespectful act' (Williams 2016). Ultimately, commemorative monuments evolved and have long been used to create and maintain public memory (Thomas 2009: 245). Given their importance to social memory, in relation to historical and archaeological studies, sharing cemetery records could be seen as a vital extension of commemorative values and practices. However, due to the breadth of attitudes and perspectives operating in different contexts, it is an act that should be pursued in collaboration with the diverse descendant and stakeholder communities that are connected to these places to ensure appropriate levels of respect and recognition are given to concerns with privacy and memory. Community consultation, fostering ongoing and open dialogue, in addition to broad digital literacy training is integral to the future of cemetery studies, tackling the complexity of ethics, access, and authority in the digital age.

\section{Open Cemeteries for Sharing Stories}

Discussions of access and distribution are only part of the digital data issue in archaeology; data reuse is a substantial concern. We cannot continue to push forward on encouraging or requiring data sharing without critically assessing and addressing reuse (Atici et al. 2012: 664, Huggett 2015: 10). The most important lesson learned in the MAP process was that, even if there is a strong public audience that is proven to be an active online community, if you build it, they will not necessarily utilize the resource. The launch of MAP was followed by a period of high traffic; however, analytics demonstrated that those visitors engaged very little with the data itself (including both searching and downloading), and 
focused more heavily on informational pages of the website. That pattern changed through more active use of the blogging end of the MAP website, which was employed in telling stories about the research and the history behind the monuments, dropping virtual breadcrumbs leading visitors directly to the datasets. These blogs pointed to critical narratives of race, inequality and resistance that could be accessed through the data. It called out family names and individuals (with the added benefit of increasing search engine optimization for genealogical researchers). When emphasis was placed on what the data could tell about the past, that data were explored and shared. ${ }^{6}$ The exceptional, arbitrary and nonconformist nature of archaeological data makes it complicated to archive, digest and reuse (Huvila 2017). This often discourages the reuse of data, with the expectation that few professionals, let alone the general public, will be interested in investing in new data analysis. Nevertheless, the citizen science movement, genealogy trend and crowdsourcing of archaeological tasks have demonstrated that there is an enormous aptitude and interest in contributing to archaeological research, if there are clear paths to engagement and connections to contemporary values, questions, and interests (see also Bonacchi et al. 2014).

Researchers and the public may have different needs in research; however, one thing that they have in common is that they both make many assumptions about the value of funerary monuments as historical records. During the early stages of the recording process in Barbados, many professional and community partners argued that it would be impossible to write histories of anyone except the white plantation owners and merchants on the island through monument analysis, and certainly not the African Barbadians who had been barred from Anglican churchyards for much of the island's history (Cook 2018). When a MAP blog post was shared for Black History Month outlining the important processes of colonial resistance and making space in cemeteries and communities based on monuments included in MAP (Figure 4) (Cook 2017), analytics, social media, and messages demonstrated a spike in

6 Although this was found to be paralleled by both professional archaeologists/historians and public audiences, engagement by public audiences was measured in this case through increased sharing on social media, comments sections, and 'pingbacks' or linking to the data on other webpages (most often on genealogy and local history pages/blogs). 
interest in using the platform to access previously marginalized historical voices. This blog in particular generated more than two thousand independent visits in a two-week period (almost double the usual impact of the blog), with half of those visitors navigating to the data sections of the site $(67 \%$ higher than other posts have generated). Reactions shared through social media were far more personal and emotional than previous posts sharing MAP, including personal stories of heritage, expressions of surprise, curiosity and self-reflection, and sentiments honouring the dead and the role that they had played. Data in isolation do not stimulate interest, or challenge conventions in archaeological practice or social memory. The more we demonstrate the potential avenues yet to be explored, the more data are valued for reuse and creative practice amongst professional and public audiences.

\section{Open Cemeteries for Inclusive Access}

Digital literacy and attitudes towards accessing raw data played a further role in reuse of MAP data. The expectations for accessible and reusable data advocated for in the open science ethos demands researchers who are trained in data management, preservation and sharing (Beagrie 2008). However, while more and more people are competent in moving through digital environments like social media, it does not mean that they are effective digital data managers or analysts, either within academia or beyond it. In academia, data reuse precipitates attitudinal shifts, including valuing collaboration and reanalysis or re-exploration of data without a sense of territorialism or competition. Outside scholarly communities (and within it), generational, cultural, and socio-economic barriers to digital literacy are a significant challenge for encouraging data reuse. MAP's first dataset of colonial cemeteries in Barbados, relevant to the island's residents but also to a global diasporic community of descendants, reflects a very complicated network of geographic, economic and sociopolitical barriers to accessing local and family history. Although access to computers and the Internet is rapidly expanding in Barbados, with $71.8 \%$ of the population identified as Internet users, this research also recognized that a web-based platform would not be the most accessible format for everyone, and hardcopies have also been shared through community archives to assist local research 
Katherine COOK - Open Data as Public Archaeology - 189

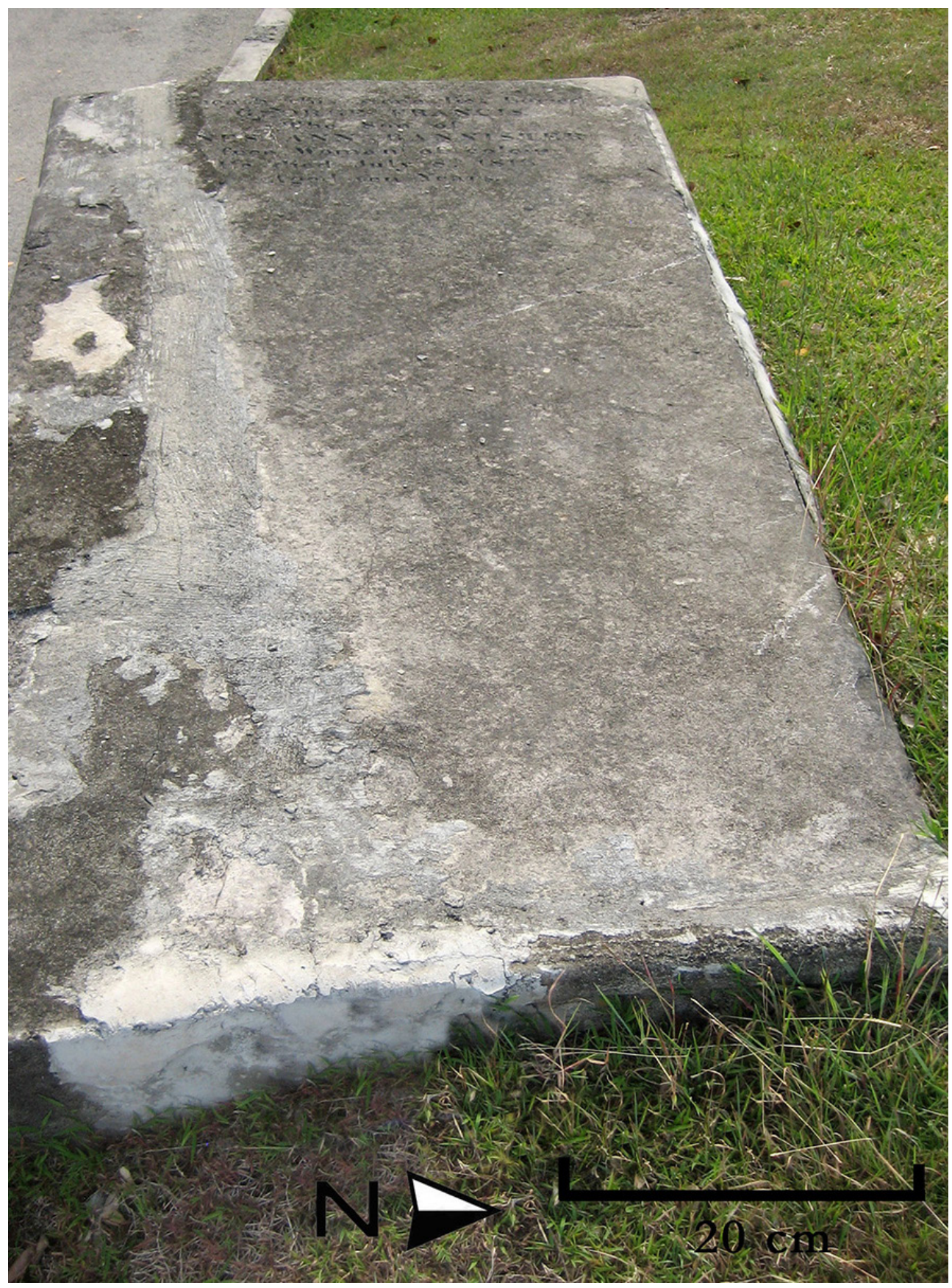

Figure 4: One monument from a storytelling blog post, commemorating George Francis, "the son of Agnes Ann Bannister free Woman of colour" who died in 1816 (photo: author). 
(World Bank 2018). Although web analytics do show users from Barbados, they are much less frequent than users from Canada, the USA, and Western Europe (in these regions, Internet users make up $80-90 \%$ of the population and ownership of personal computers, home Internet access and mobile smart technology is $25-50 \%$ higher). While MAP sought to increase access through providing both web- and community based records, in recognizing the complexity of colonial legacies in Caribbean heritage, it is important to critically reflect on the ways in which digital archaeology is never neutral or apolitical. Use and analysis of open data necessitates high levels of digital literacy, and even at times access to advanced computing and strong Internet access. Moreover, there are often even more complex attitudinal shifts that need to occur, including perceptions, assumptions and expectations of archaeology, heritage, and who has the right/interest to access them. Open science intersects democratizing and decolonizing practices in scholarship; however, the reliance on technology and digital literacy to achieve these goals does not necessarily remove all barriers for all communities (Suber 2012: 26-27).

\section{Conclusion}

Like many digital data projects, MAP continues to evolve, exploring solutions to ongoing challenges in digital preservation and sustainability. The successes and failures of this experiment in open data have demonstrated that digital cemetery projects must, at every level, be community projects. The collection of data itself is far from a neutral activity and needs to be framed by consultation and collaboration. Whether we record one monument to the dead or a thousand, whether the memorial was raised three years ago or three hundred, every note, photograph, 3D model, and map has the potential to impact living communities and historical narratives in both positive and negative ways. Therefore, our approach must always be thoughtful, inclusive, and respectful from the early stages of each project through to the end. The next steps for open cemetery data are to gather more systematic feedback and perspectives from users to ensure that these digital platforms continue to be developed and enhanced for ease of access and community value. 
At the same time, creative open cemetery projects can only be encouraged by providing support and recognition for the effort that goes into their development, and the real impact that they have. Within academia, this means ensuring that funding, hiring and promotion reward non-traditional research outputs. For communities, this means advocating more appropriate compensation or recognition of labour, ideas, and contributions as well as honouring community voices and expertise.

The sharing of cemetery data must be first and foremost community minded, focusing on free and, as much as possible, accessible information, digital literacies, ethical practice, and motivations for accessing digital archives. Online platforms can and should be vehicles for local heritage and narratives as much as raw data for querying and analysis because together, stories and data demonstrate the value of mortuary archaeology and the preservation of historical cemeteries (in physical and virtual forms). Cemeteries have always been public spaces and meaningful places for the living, but they have also changed over time to reflect changing attitudes and experiences of these living communities. Digital cemetery initiatives must equally be adaptable places for the living to explore and engage. If they are not created from the perspective of who might use them, why and how, open cemeteries may end up equally neglected as their physical counterparts.

\section{Acknowledgements}

The MAP project was supported by the Department of Archaeology, University of York and was developed through participation in Michigan State University's Institute for Digital Archaeology Method and Practice. The cemetery research included in this paper was a doctoral project that was funded by the Social Sciences and Humanities Research Council (Canada) and the University of York, with permissions from the Anglican Diocese of Barbados, the Barbados Archives and the Barbados Museum and Historical Society. Further thanks to the reviewers for their detailed and insightful feedback on this paper. 


\section{References}

Atici, L., Whitcher Kansa, S., Lev-Tov, J., and Kansa, E. C. 2012. Other people's data: a demonstration of the imperative of publishing primary data. Journal of Archaeological Method and Theory 20(4), 663-81.

Bonacchi, C., Bevan, A., Pett, D., Keinan-Schoonbaert, A., Sparks, R., Wexler, J. and Wilkin, N. 2014. Crowd-sourced archaeological research: the MicroPasts project. Archaeology International 17, 61-68.

Camp, S. L. 2017. Experiments in Digital Archaeology. Retrieved on 3 June 2018 from WWW https://staceylcamp.wordpress. com/blog/

Cannon, A. and Cook, K. 2015. Infant death and the archaeology of grief. Cambridge Archaeological Journal 25, 399-416.

Cook, K. 2011. Deathscapes: Memory, Heritage and Place in Cemetery History. Unpublished MA Thesis submitted to McMaster University, Hamilton, Canada.

Cook, K. 2016a. The Monumental Archive Project. Retrieved on 3 June 2018 from WWW www.monumentalarchiveproject.com

Cook, K. 2016b. New World Families: Building Identity, Memory and Heritage in Transatlantic Contexts. Unpublished PhD thesis, Department of Archaeology, University of York.

Cook, K. 2017. The colour of commemoration: a history of slavery \& emancipation in five monuments. The Monumental Archive Project Blog. Retrieved on 3 June 2018 from WWW https:// monumentalarchiveproject.wordpress.com/2017/02/22/colourof-commemoration/

Cook, K. 2018. Negotiating memory: funerary commemoration as social change in Barbados. African \& Black Diaspora: An International Journal. DOI: 10.1080/17528631.2017.1412929

Dundee Howff Conservation Group 2017. Dundee Howff Sketchfab models. Retrieved on 3 June 2018 from WWW https://sketchfab. com/dundeehowff?fref $=g c$ 
Huggett, J. 2015. Digital haystacks: open data and the transformation of archaeological knowledge. In A.T. Wilson and B. Edwards (eds), Open Source Archaeology: Ethics and Practice. Berlin, De Gruyter Open, 6-29.

Huvila, I. 2017. Being FAIR when archaeological information is MEAN: miscellaneous, exceptional, arbitrary, nonconformist. Presentation at the Centre for Digital Heritage conference, Leiden, the Netherlands. Retrieved on 3 June 2018 from WWW http://www.istohuvila.se/node/526

Judge, E. F. and Brown, E. 2017. Pokémorials: placing norms in augmented reality. University of British Columbia Law Review, Vol. 50: 971-1016.

Kansa, E. C. 2010. Open context in context: cyberinfrastructure and distributed approaches to publish and preserve archaeological data. SAA Archaeological Record 10(5), 12-16.

Kansa, E. C. 2012. Openness and archaeology's information ecosystem. World Archaeology 44(4): 498-520.

Kansa E. C., Whitcher, S. and Arbuckle, B. 2014. Publishing and pushing: mixing models for communicating research data in archaeology. International Journal of Digital Curation 9(1), 5770.

Kramer, A.-M. 2011. Mediatizing memory: history, affect and identity in Who Do You Think You Are? European Journal of Cultural Studies 14(4), 428-445.

Lawrence-Archer, J. H. 1875. Monumental Inscriptions of the British West Indies from the Earliest Date. London, Chatto and Windus.

Lucas, G. 2012. Understanding the Archaeological Record. Cambridge, Cambridge University Press.

Lupton, D. 2014. Digital Sociology. Abingdon, Routledge.

Márquez-Grant, N. and Errickson, D. 2017. Ethical considerations: an added dimension. In T. Thompson and D. Errickson (eds), Human Remains: Another Dimension: The Application of Imaging to the Study of Human Remains. London, Academic Press, 193-202. 
Oliver, V. L. 1915. Monumental Inscriptions in the Churches and Churchyards of the Island of Barbados, British West Indies. London, Mitchell Hughes and Clarke.

Richardson, L-J. and Lindgren, S. 2017. Online tribes and digital authority: what can social theory bring to digital archaeology? Open Archaeology 3: 139-148.

Shapira, S. 2017. Yolocaust. Retrieved on 3 June 2018 from WWW https://yolocaust.de

Suber, P. 2012. Open Access. MIT Press, Cambridge, MA.

Thomas, K. 2009. The Ends of Life: Roads to Fulfilment in Early Modern England. Oxford, Oxford University Press.

Thorne, H. n.d.. Monumental Inscriptions of Barbados Collected on the Spot, 1888-1902. Unpublished record on file with Barbados Museum \& Historical Society. Shilstone Library, Bridgetown, Barbados.

Tibbo, H. 2003. Primarily history in America: how U.S. historians search for primary materials at the dawn of the digital age. The American Archivist 66(1), 9-50.

Williams, H. M. R. 2016. What's wrong with photographing the dead? Archaeodeath. Retrieved on 3 June 2018 from WWW https://howardwilliamsblog.wordpress.com/2016/01/31/whatswrong-with-photographing-the-dead/

World Bank 2018. Internet Users Statistics. Retrieved on 3 June 2018 from WWW https://data.worldbank.org/indicator/IT.NET. USER.ZS 